[33] Sohwartzenbach. Ann. der Chem. u. Pharm., 1865, 133, 185.

[34] E. Mrlion et A. Commatlle. $C . R$. de l'Acad. des Sc., 1865, 60, 118.

[35] E. Mrluon et A. Commatlle. C. R. de l'Acad. des Sc., 1865, 61, 221.

\title{
AMÉLIORATION PAR LE LAVAGE DE LA CRÈME DE LAIT ET DE SÉRUM DE FROIMAGERIE (1)
}

\author{
par le Dr Oтto GRATZ
}

Institut Royal Hongrois de Rэchørchas laitières, Magyaróvìr.

Dans les pays de petites exploitations agricoles, les circonstances entraînent fréquemment, soit la création de "stations d'écrémage ", soit l'écrémage à la ferme. Il arrive alors sauvent que la crème est expédiée à la laiterie, non pas chaque jour; mais seulement une ou deux fois par semaine. On trouve des exemples de cette façon de procéder même dans les pays dont l'industrie beurrière est très importante. En Finlande orientale, par exemple, région de faible population, les agriculteurs n'envoient leur beurre, soit directement de leur ferme, soit par l'intermédiaire de la "station d'écrémage ", que deux ou trois fois par semaine à la beurrerie. Nous-rencontrons très fréquemment ce procédé outre-mer, par exemple aux Etats-Unis, en Argentine, en Nouvelle-Zélande, etc.

Il va sans dire qu'une telle crème, vieille de plusieurs jours, ne saurait fournir un beurre de première qualité. Quelle que soit sa richesse en corps gras - ou ce qui revient au même, quelque faible que soit la proportion des composants non gras, source, comme on le sait, de la décomposition - la crème aigrit, sa surface se recouvre d'Oidium lactis, qui décompose la graisse, de nombreuses moisissures apparaissent, par lesquelles la graisse est aussi fréquemment attaquée.

Les "stations d'écrémage » étant rarement pourvues des appareils de réfrigération qui permettraient de maintenir une température au-dessous du point de congélation, la crème est conservée jusqu'à la livraison tout au plus entre des morceaux de glace. Le plus souvent cependant, elle reste simplement à la température de la cave ou du dépôt, ce qui permet d'abord l'attaque par divers microbes des composants non gras, tels que le sucre de lait et les matières albuminoïdes, et, par suite, la décomposition de la graisse elle-même.

Pour pouvoir pasteuriser une crème livrée avec un tel degré d'acidité, on a coutume, dans les pays d'outre-mer notamment (Australie, Argentine, Canada, Kénia, Nouvelle-Zélande, Etats-Unis, etc.), de neutraliser les acides avec différentes bases et d'améliorer considérablement de cette façon la qualité du beurre. Par ce procédé, cependant, les acides sont simplement transformés en divers lactates,

(1) Cet article a paru également dans Molkerei Zeitung (Hildesheim). 
qui subsistent, de même que les matières albuminoïdes, en partie attaquées, les produits de la décomposition de l'albumine et, en outre, une petite quantité de graisse décomposée, facteur d'une décomposition plus étendue.

Toutes ces matières donnent naturellement à la crème et au beurre qu'elle produit une odeur et un goût désagréables. Comme la pasteurisation suit la neutralisation, il n'est plus question de microbes, mais les "enzymes » résistant à la chaleur n'en subsistent pas moins, et ceux-ci se chargent d'accélérer la décomposition du beurre. Comme nous le montrons, la température de pasteurisation ne détruit nullement dans la crème les enzymes qui décomposent la graisse.

Celles-ci restent donc actives dans le beurre produit avec la crème pasteurisée. La partie non grasse de la crème et du beurre est le siège le plus important de la corruption. La partie non grasse n'étant pas autre chose que le lait écrémé (lait maigre), nous pouvons aussi considérer la crème comme un lait très gras. Même après l'écrémage le plus poussé, la crème contient encore plus de $50 \%$ de lait maigre. Enlever celui-ci à l'aide du "séparateur ", par le moyen de la force centrifuge, n'est pas possible, car une crème contenant 45 à $50 \%$ de corps gras s'obtient déjà difficilement, ou avec perte de graisse, et la proportion de la graisse s'élève dans le lait écrémé.

Ce serait un grand progrès que de pouvoir séparer de cette crème, vieille de plusieurs jours, la partie "lait maigre" et, avec elle, les différents facteurs de décomposition : enzymes, ete. On épurerait ainsi la partie grasse et on ajouterait ensuite du "lait maigre " frais. Ce procédé permettrait sûrement d'obtenir un beurre de meilleure qualité et de composition supérieure.

La séparation de la partie non grasse de la crème se présente encore à nous d'une autre manière. Le beurre de sérum de fromagerie est, comme on le sait, moins bon, d'odeur et de goût moins fins, d'apparence plus grasse. Le beurre de sérum ne contient, cependant, aucune substance caséeuse : seulement, à côté de l'albumine et de la globuline, la matière albuminoïde provenant de la caséine et séparée par la présure (albumine de petit-lait ou albumose). Ces matières donnent au beurre de sérum un goût de fromage. La présure contenue dans ledit beurre continue dans celui-ci son action décomposante sur les matières albuminoïdes. Toutes ces circonstances influent très défavorablement sur la qualité du beurre de sérum et c'est une tâche importante que de travailler à une a mélioration dans ce sens.

Il faut essayer de récupérer dans un produit meilleur que n'est le sérum de fromagerie, la précieuse graisse de lait qui ne se laisse pas englober dans le caillé et qui passe inévitablement dans ce sérum. Il est bien connu que la crème de sérum donne, si on lui ajoute une cer- 
taine quantité de crème de lait, un beurre bien supérieur, appelé, en Suisse, "beurre mélangé " (Mischelbutter).

Si l'on pouvait séparer complètement le sérum dans la crème correspondante, comme cela paraît possible par la centrifugation, et le remplacer par du lait plein ou maigre, ce résultat, joint à la pasteurisation et à la maturation de la crème par les cultures pures, permettrait certainement d'atteindre une amélioration importante de la qualité du beurre de sérum et augmenterait par suite notablement les bénéfices de la fromagerie.

$$
\text { * * * }
$$

Comment peut-on cependant réaliser l'idée de séparer complètement le lait maigre plus ou moins altéré de la crème de lait vieille de plusieurs jours, ou le sérum de la crème de fromagerie ? Il y a là pour la technique, un beau et utile problème à résoudre, dont la solution serait de grande importance.

L'idée qui se présente à l'esprit du producteur de beurre est de séparer, de chasser par le lavage la partie non grasse de la crème. Nous lavons bien plusieurs fois les beurres tout prêts pour en séparer le babeurre et, avec lui, les matières albuminoïdes, le sucre de lait, etc. Ou bien, encore, nous rafraîchissons du vieux beurre en le lavant plusieurs fois et en le traitant ensuite avec du lait complet, du lait maigre ou du babeurre. Si l'on obtient ainsi par le lavage une amélioration de la qualité du beurre, ce doit être aussi le cas lorsque nous lavons la crème. C'est ce que doivent expliquer les expériences décrites cíaprès.

\section{DESCRIPTION DES EXPERIENCES}

$\mathrm{Au}$ cours de la description des expériences, lorsqu'il sera simplement question d'un "lavage " répété, ce terme aura toujours la signification suivante : la crème vieille de plusieurs jours a été délayéedans 4 à 5 fois sa quantité d'eau pure, légèrement tiède, mélangée, puis centrifugée. Dans de nombreux cas, cela a été répété 2 fois avec de l'eau ; au total donc, le lavage a été effectué successivement avec 3 eaux différentes, puis la crème a été centrifugée. Après le dernier lavage, on a mélangé avec du lait maigre frais; le mélange a été naturellement centrifugé de nouveau aussi eomplètement que possible et la crème ainsi obtenue a été transformée en beurre. Nous avons done délayé de cette façon la partie non grasse de la crème une ou plusieurs fois avec de l'eau, puis une dernière fois avec du lait écrémé; nous avons pour ainsi dire rincé les particules de graisse et chassé ensuite, en centrifugeant, l'eau de rinçage, puis le lait écrémé, c'est-à-dire les composants de la crème, dangereux pour la qualité du beurre, qui s'y trouvaient dissous ou en suspension. En d'autres termes, nous avons chassé la partie non grasse de la crème plus ou moins décom- 
posée et nous l'avons remplacée par une partie semblable, mais fraî-. che. A la fin, il ne restait dans la crème qu'une quantité pratiquement insignifiante de la partie non grasse primitive.

Ce procédé demande en vérité un travail assez compliqué, mais une mise au point des appareils employés - cuves de brassage, appareils centrifugeurs - permettra de le réaliser sans difficultés spéciales.

Expérience 1. - Après son obtention, la crème reste 7 jours à la température du dépôt. Son degré d'acidité est alors de $30^{\circ} 2 \mathrm{~S}$. H. Elle est divisée en 2 quantités égales. La $1^{\text {re }}$ partie est transformée en beurre sans lavage préalable, après pasteurisation et maturation avec une culture pure. L'autre partie est préalablement lavée. La crème non lavée donne un beurre de goût rance et âcre.

La crème lavée trois fois à l'eau fraîche et une fois avec du lait écrémé a un degré d'acidité maximum de $5^{04} \mathrm{~S}$. H. Pasteurisée et mûrie dans les mêmes conditions que la première, elle donne un beurre de bien meilleure qualité. Pour voir si le lavage a également une influence sur la décomposition de la graisse dans le beurre, on a maintenu le beurre un temps assez long dans des capsules dans lesquelles il a été fortement pressé et couvert d'une feuille d'étain imperméable à l'air, puis on a déterminé son degré d'acidité. Les chiffres obtenus sont indiqués au tableau I :

TABLEAU I.

DEGRÉ D'AGIDITÉ DE LA GRAISSE DANS LE BEURRE SELON QU'IL PROVIENT D'UNE GRĒME LAVÉE OU D'UNE GRÈME NON LAVEE,

Nombre de jours après

l'obtention de la erème
Degré d'acidité de la graisse dans le beurre produit avec de la crème

$\begin{array}{cr}\text { non lavée } & \text { lavée } \\ 3,33 & 3,12 \\ 10,09 & 4,06 \\ 12,89 & 6,88 \\ 13,71 & 7,42 \\ 15,28 & 4,15 \\ 17,58 & 5,28 \\ 21,48 & 6,15 \\ 26,22 & 7,45 \\ 32,48 & 7,96\end{array}$

Ces ehiffres montrent nettement la grande influence du lavage de la crème sur la décomposition de la graisse dans le beurre. Dès le début, cette décomposition progresse beaucoup plus vite dans le beurre de crème non lavée et elle est, au bout de 70 jours, terme de l'expérience, quatre fois plus élevée que dans la graisse de beurre de crème lavée. La crème ayant été pasteurisée avant d'être transformée 
. en beurre, on peut en conclure que les enzymes de la graisse ont supporté sans dommage la température de pasteurisation.

Expérience II. - Après production, la crème reste 21 jours à la température ordinaire, ce qui représente un long stage à une température défavorable, telle que cela arrive rarement dans la pratique.

La crème est alors recouverte d'une puissante végétation d'Oidium bactis. Elle contient des levures et on voit aussi à sa surface quelques colonies de moisissures. L'acidité atteint $33^{\circ} \mathrm{S}$. H. La crème est de nouveau pasteurisée en 2 parties, l'une lavée, l'autre non Javée. A près acidification dans un bouillon de culture, elle est transformée en beurre. Le beurre est ensuite jugé d'après le procédé des points (1) et son degré d'acidité est établi. L'examen du beurre est soumis à 3 juges, qui prononcent leur jugement chacun séparément.

Les coefficients obtenus par les beurres de crème non lavée et de crème lavée sont indiqués dans le tableau II :

TABLEAU II.

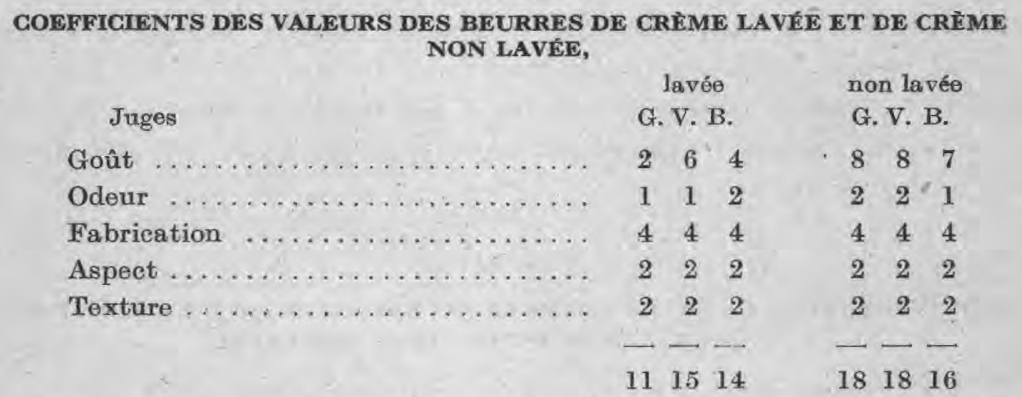

La crème lavée trois fois avec de l'eau et une fois avec du lait écrémé, n'avait plus qu'une acidité de $6045 \mathrm{~S}$. H. Pasteurisé, mûri. et baratté, le beurre ainsi produit reçoit dans le jugement ci-dessus, un coefficient total supérieur à celui du beurre de crème non lavée. L'influence favorable du lavage sur la qualité du beurre est indéniable, Tous les juges ont accordé des coeffieients supérieurs au beurre de crème lavée et le coefficient maximum a été presque atteint.

L'acidité de la graisse dans le beurre de crème lavée et non lavée est indiquée au tableau III. Comme dans la première expérience, nous voyons nettement que, dans le beurre de crème non lavée, la graisse se décompose beaucoup plus vite que lorsque la vieille crème a été bien lavée à fond 3 fois à l'eau et une quatrième fois au lait écrémé avant d'être transformée en beurre.

Expériences III et IV. - Dans ces expériences, la crème a été conservée respectivement 14 et 21 jours dans une chambre froide à

(1) Pour le jugement du beurre, les coefficients maximum étaient ainsi fixés : Goût : 10 - Odeur : 2 - Fabrication : 4 - Aspect : 2 - Texture : 2 - Total : 20 . 
une température moyenne de 4 à $8^{\circ} \mathrm{C}$. Elle a été ensuite, comme dans les expériences précédentes, divisée en deux parties, l'une lavée, l'autre non lavée, séparément pasteurisées, acidifiées et transformées en beurre. L'acidité de la crème s'élève pendant le dépôt respective-

TABLEAU III.

ACIDITE DE LA GRAISSE DANS LE BEURRE DE GREME NON LAVEE ET LAVÉE,

Nombre de jours

après l'obtention

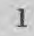

8

13

20

28

41

48

55

78
Acídité de la graisse dans le beure de crèmo non lavée lavée

4,08
12,55
15,96
21,39
26,59
35,39
40,27
44,84
51,93

3,06

7,43

8,76

9,16

10,90

14,88

15,36

16,71

19,46

ment à $27^{\circ}$ et à $28^{\circ} 3 \mathrm{~S}$. H. Le lavage l'abaisse respectivement à $7^{\circ} 4$ et $6^{\circ} 5 \mathrm{~S}$. H. La température de la chambre froide n'a pas pu être refroidie pendant le temps de l'expérience. Le lavage a été effectuécomme précédemment, 3 fois avec de l'eau et une fois avec du lait écrémé frais. Les résultats sont indiqués dans les tableaux IV et V.

TABLEAU IV.

GOEFFICIENT DU BEURRE DE GRËME LAVEE ET DE GRẺME NON LAVÉE,

\section{Expérience III \\ non lavée}

V. B. K. V. B. K.

Goût $\ldots \ldots \ldots \ldots \ldots \ldots \ldots \ldots$
Odeur $\ldots \ldots \ldots \ldots \ldots \ldots \ldots \ldots$
Fabrication $\ldots \ldots \ldots \ldots \ldots \ldots$
Aspect $\ldots \ldots \ldots \ldots \ldots \ldots \ldots$
Texture $\ldots \ldots \ldots \ldots \ldots \ldots \ldots$

Ensemble
Expérience IV lavée

G. V. B.

G. V. B. $\begin{array}{llllll}6 & 6 & 5 & 8 & 7 & 7\end{array}$

$\begin{array}{llllll}1 & 1 & 2 & 1 & 1 & 1\end{array}$

$4 \quad 4 \quad 4 \quad 4 \quad 4 \quad 4$

$\begin{array}{llllll}2 & 2 & 2 & 2 & 2 & 2\end{array}$

$\begin{array}{llllll}2 & 2 & 2 & 2 & 2 & 2\end{array}$

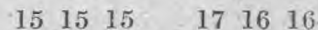

Les chiffres du tableau $V$ nous montrent que l'influence du lavage de la crème sur la qualité du beurre est moins appréciable dans cette expérience que dans les précédentes. Dans l'expérience III, le beurre de crème non lavée est même un peu meilleur que le beurre de crème lavée. Dans l'expérience IV, le beurre de crème lavée n'est que de quelques points supérieur.

Nous ne pouvons nous expliquer ce résultat surprenant. Une troisième expérience, que nous n'indiquerons pas ici en détail, portant sur de la crème conservée froide, donna le même résultat. 
Le lavage de la crème a eu cependant, même dans les eas ei-dessus, une influence favorable sur la décomposition de la graisse dans le beurre. C'est ce que montre le tableau V. Les enzymes décomposant la graisse ont été manifestement éloignées de la crème par le lavage, puisque la décomposition de la graisse dans le beurre de crème lavée est bien moins importante.

TABLEAU V.

ACIDITÉ DE LA GRAISSE DANS LE BEURRE DE GRËME NON LAVÉE ET DE CRËME LAVÉE,

Expérience III

$\begin{array}{rccc}\text { Jours } & \begin{array}{c}\text { Acidité de la graisse dans } \\ \text { le beurre de crème }\end{array} & \text { Jours } \\ & \text { non lavée } & \text { lavée } \\ 7 & 3,70 & 2,11 & 5 \\ 20 & 11,67 & 4,07 & 13 \\ 27 & 13,28 & 4,03 & 26 \\ 34 & 16,75 & 4,25 & 33 \\ 58 & 23,13 & 4,22 & 40 \\ 64 & 25,84 & 4,73 & 63\end{array}$

Expérience IV

Acidité de la graisse dans le beurre de crème non lavée lavée

$\begin{array}{ll}1,93 & 1,07 \\ 3,98 & 2,38 \\ 5,89 & 2,83 \\ 6 & 3,11 \\ 6,16 & 3,45 \\ 7,87 & 3,81 \\ 8,40 & 3,43\end{array}$

Expériencés V à XII. - Les expériences précédentes ne laissent aucun doute sur l'amélioration du goût et de la qualité du beurre obtenus en lavant trois fois la crème à l'eau et ensuite une fois au lait écrémé. Le fait que le lavage à l'eau doit avoir lieu plusieurs fois (2 fois au moins) avant de passer au lavage au lait écrémé, est montré par les 8 expériences suivantes qui prouvent qu'un seul lavage de la erème dans 5 fois son volume d'eau, à la température de $20-30^{\circ}$, est loin d'avoir, sur la qualité du beurre, une influence aussi favorable que deux à trois lavages successifs. L'acidité de la crème a été également, dans ces expériences portant sur un seul lavage, abaissée respectivement de $19^{\circ} 6$ et $32^{\circ} 3 \mathrm{~S}$. H. à $3^{\circ} 6$ et $5^{\circ} 3 \mathrm{~S}$. H. Les coefficients du beurre dans les 8 expériences montrent les différences suivantes :

$\begin{array}{llc}\text { Beurre de crème non lavée } \ldots \ldots \ldots \ldots \ldots \ldots & \text { frais } & 10 \text { jours après } \\ \text { Beurre de crème lavée } \ldots \ldots \ldots \ldots \ldots \ldots \ldots & 15-19 & 11-16 \\ \end{array}$

Le beurre de crème lavée une fois n'est done supérieur que de peu.

Dans ces expériences, l'eau de lavage a été soumise à un examen. Elle contenait toujours un peu de graisse, car dans les 8 expériences, la proportion de graisse variait entre 0,05 et $0,62 \%$. Dans un cas, elle s'élevait même, pour une cause inexpliquée, à $1 \%$. Le tableau VI indique les chiffres concernant l'acidité et la proportion des acides gras volatils dans l'eau de lavage: 


\section{TABLEAU VI.}

ACIDITÉ DE LA PREMIÉRE EAU DE LAVAGE ET PROPORTION DES AGIDES GRAS VOLATILS.

$\begin{array}{cccc}\text { Expérience } \mathrm{n}^{\circ} & \begin{array}{c}\text { Température de } \\ \text { lavage en } \\ \text { degrés centigrades }\end{array} & \begin{array}{c}\text { Degré } \\ \text { d'acidité }\end{array} & \begin{array}{c}\text { Acides gras volatils } \\ \text { distillés sur } 200 \mathrm{~cm}^{3}\end{array} \\ \text { V } \ldots \ldots \ldots \ldots \ldots & 20 & 2,5 & 5,1 \\ \text { VI } \ldots \ldots \ldots \ldots & 20 & 3,36 & 7,70 \\ \text { VII } \ldots \ldots \ldots \ldots & 20 & 4,30 & 9,60 \\ \text { VIII } \ldots \ldots \ldots \ldots & 20 & 3,80 & 13,25 \\ \text { IX } \ldots \ldots \ldots \ldots & 20 & 4,40 & 9 \\ \text { X } \ldots \ldots \ldots \ldots \ldots & 30 & 3,40 & 6,85 \\ \text { XI } \ldots \ldots \ldots \ldots . & 30 & 3,70 & 7,45 \\ \text { XII } \ldots \ldots \ldots \ldots . & 30 & 3,60 & 9,70\end{array}$

Ces chiffres montrent nettement que le premier lavage éloigne déjà de la crème une importante quantité d'acides et témoigne par là de la valeur du procédé. L'acidité de la graisse dans le beurre de crème lavée une fois et de la crème non lavée sont indiquées au tableau VII :

TABLEAU VII.

AGIDITÉ DE LA GRAISSE DANS LE BEURRE DE GREME LAVÉE UNE FOIS,

Expérience no

V. $\ldots \ldots \ldots$
VI $\ldots \ldots \ldots$
VII $\ldots \ldots \ldots$
VIII $\ldots \ldots \ldots$
IX $\ldots \ldots \ldots$
$X \ldots$
X $\ldots \ldots \ldots$
XI $\ldots \ldots \ldots$
XII $\ldots \ldots \ldots$

Acidité de la graisseddans le beurre de crème :

non lavée fraîche de 10 jours 0,70

0,65

1,02

0,82

1,02

1,02

0,82

1,02

2,28
2,41
5,51
1,94
6,49
5,51
1,94
6,49

$\begin{array}{cc}\text { fraîche } & \text { de } 10 \text { jour } \\ 1,02 & 2,39 \\ 0,60 & 1,55 \\ 0,92 & 3,77 \\ 1,02 & 3,06 \\ 1,10 & 2,53 \\ 1 & 2,65 \\ 1,02 & 3,98 \\ 1,26 & 2,94\end{array}$

Les chiffres de ce tableau montrent de nouveau à l'évidence que,. même dans le beurre de crème lavée une seule fois, la décomposition de la graisse est moins élevée que dans le contrôle correspondant.

Expérience avec la crème de sérum de fromagerie. - Dans. cette expérience, on a utilisé de la crème de sérum recueillie pendant. une semaine et conservée dans une chambre froide.

La quantité s'élevait à la fin à 80 litres, dont il fut fait deux parts. La première, soit 40 litres, ne subit aucun traitement préalable. La seconde fut délayée 2 fois dans 200 litres d'eau chaque fois, lavée, centrifugée, puis délayée et centrifugée une troisième fois avec 200 litres de lait écrémé.

La première eau de lavage contenait $0,8 \%$, la seconde $0,05 \%$. 
de graisse. Le petit-lait mélangé de lait écrémé contenait après la dernière centrifugation $0,37 \%$ de graisse.

Le procédé du lavage amène done certainement une légère diminution de la quantité de beurre produite, car la centrifugation répétée fait perdre chaque fois une certaine quantité de graisse.

Le tableau VIII contient les coefficients affectés dans cette expérience aux beurres de crèmelavée et de crème non lavée. Le tableau IX indique la réaction de l'acidité de la graisse dans le beurre.

TABLEAU VIII.

COEFFIGIENTS DU BEURRE DE GRËME DE PETIT-LAIT NON LAVÉE ET LAVÉE.

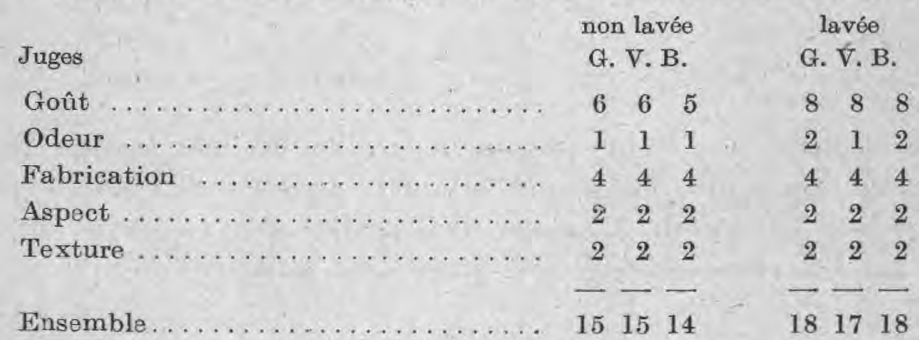

TABLEAU IX.

ACIDITÉ DE LA GRAISSE DANS LE BEURRE DE GRÈME DE PETIT-LAIT LAVÉE ET NON LAVEEE,

Nombre de jours après l'obtention

2

9

16

40

46

55
Acidité de la graisse dans le beurre de crème non lavée lavée

2,13

2,54

2,92

6,83

8,14

12,69
2,39

2,28

2,35

2,29

2,79

4,51

Les chiffres des tableaux VIII et IX montrent nettement que le lavage de la crème de petit-lait permet d'obtenir un beurre meilleur et plus riche que celui de crème non lavée. A la fois comme goût et comme odeur, ce beurre a été trouvé supérieur par tous les juges. Ce résultat a d'ailleurs été souvent constaté dans la pratique, ainsi que me l'ont dit des propriétaires de laiteries et de fromageries. L'élévation de la qualité du beurre compenserait la perte de quantité.

\section{POSSIBILITÉS DE DÉVELOPPEMENT DU PROCÉdÉ}

Le procédé du lavage de la crème peut être encore perfectionné sous divers rapports. Certaines indications doivent être données à ce sujet. Pour neutraliser les acides et les enlever complètement, nous pouvons dissoudre dans la première eau de lavage une base telle que le bicarbonate de soude, le phosphate trisodique, le lait de chaux ou 
l'un des produits neutralisants que l'on trouve dans le commerce sous différents noms, par exemple le "Wyandotte C. A. S. ", qui est un produit éprouvé. La seconde eau de lavage doit être pure, libre de germes, et si possible stérilisée. On peut encore y dissoudre un peu d'acide citrique et de sucre de lait. On sait, d'après les recherches récentes, que certains parfums et certains goûts apparaissent dans la crème mûrie à l'acide citrique sous l'action de certaines bactéries lactiques, telles que le Strept. citrovorus de HaMmER et les betacoques d'ORLA-JENSEN. Un nouveau progrès vers la disparition complète des goûts et odeurs indésirables doit être atteint en faisant passer dans la crème, après adjonction de la seconde eau de lavage, un produit dégasifiant, qui donne, comme on le sait, d'excellents résultats, particulièrement à l'époque de la nourriture avec les raves. Pour le lavage de la crème de petit-lait, il est peut-être encore plus avantageux d'employer du bon lait complet au lieu du lait écrémé.

M. J. Csiszar, diplômé d'Agriculture, adjoint scientifique à l'Institut de Recherches, a pris part aux expériences ci-dessus.

\title{
RÉSUMé
}

En une série d'expériences, il a été démontré que la crème de lait et de sérum de fromagerie était améliorée par des lavages répétés à l'eau et au lait écrémé et qu'elle donnait un beurre meilleur et plus riche. Des indications complémentaires seront données par la suite sur les perfectionnements éventuels du procédé.

\section{RECHERCHE ET NUMÉRATION DU COLI-BACILLE DANS LE LAIT PAR LA MÉTHODE DU ROUGE NEUTRE}

\author{
par THÉodor VASSILEFF \\ Docteur-Vétérinaire.
}

(Travail du Laloratoire d'Hygiène de la Faculté de Médecine et du Laboratoire des Industries animales de l'Ecole vétérinaire de Lyon.)

\section{INTRODUCTION}

\section{LES SOURCES DE CONTAMINATION DU LAIT}

Par sa composition chimique, par sa réaction, par la lenteur de son refroidissement, le lait, si on ne prend pas la précaution d'abaisser fortement sa température après sa récolte, constitue, pour les nombreux microbes qu'une traite malpropre y aura déversés, un excellent milieu de culture, et, malgré la phase " bactéricide " qui commence et se poursuit quelques heures après la mulsion, la plupart des germes qui l'ont ensemencé y pullulent bientôt.

Les sources de contamination du lait sont nombreuses : 